\title{
Erratum
}

DOI $10.1007 / \mathrm{s} 00712-006-0183-9$

\section{Non-convex Technologies and Cost Functions: Definitions, Duality and Nonparametric Tests of Convexity (Journal of Economics 81(2): 155-192)}

\author{
Walter Briec, Kristiaan Kerstens \\ and Philippe Vanden Eeckaut
}

Received December 22, 2005

Published online: April 5, 2006

(C) Springer-Verlag 2006

There is a minor typo on page 168 in line 2 of the proof of Lemma 1 . The statement should read:

Equivalently, we get $\delta \leq \min _{n \in I\left(x_{k}\right)}\left(\frac{x_{n}}{x_{k n}}\right)$ and $\delta \geq \max _{m \in J\left(y_{k}\right)}\left(\frac{y_{m}}{y_{k m}}\right)$ for $\delta \in \Gamma$.

There is a typographical error on the same page 168 in the closed form expressions for the radial input efficiency measure $E_{i}(x, y)$. The statement should read: 
Proposition 2: $E_{i}(x, y)$ on non-convex technologies $T^{N C, \Gamma}$ is computed:

$$
E_{i}(x, y)=\left\{\begin{array}{c}
(\text { i }) \min _{\left(x_{k}, y_{k}\right) \in B(x, y, \Gamma)}\left\{\max _{n \in I\left(x_{k}\right)}\left(\frac{x_{k n}}{x_{n}}\right)\right\} \quad \text { for } \Gamma=V R S \\
\min _{\left(x_{k}, y_{k}\right) \in B(x, y, \Gamma)}\left\{\max _{m \in J\left(y_{k}\right)}\left(\frac{y_{m}}{y_{k m}}\right) \cdot \max _{n \in I\left(x_{k}\right)}\left(\frac{x_{k n}}{x_{n}}\right)\right\} \\
\text { for } \Gamma \in\{C R S, N I R S\} \\
\left(\text { iii) } \min _{\left(x_{k}, y_{k}\right) \in B(x, y, \Gamma)}\left\{\max \left(\max _{m \in J\left(y_{k}\right)}\left(\frac{y_{m}}{y_{k m}}\right), 1\right) \cdot \max _{n \in I\left(x_{k}\right)}\left(\frac{x_{k n}}{x_{n}}\right)\right\}\right. \\
\text { for } \Gamma=N D R S .
\end{array}\right.
$$

The same holds true in the proof of Proposition 2 on page 185, lines 3-4. It should read: since $x \geq x_{k}$, clearly $x_{k n}>0 \Rightarrow x_{n}>0$. Thus, $\max _{n \in I\left(x_{k}\right)}\left(\frac{x_{k n}}{x_{n}}\right)=\left[\min _{n \in I\left(x_{k}\right)}\left(\frac{x_{n}}{x_{k n}}\right)\right]^{-1}$. Consequently, $E_{i}\left(x, y \mid S^{S D, \Gamma}\left(x_{k}, y_{k}\right)\right)=$ $\min \left\{\lambda: \lambda \geq\left[\min _{n \in I\left(x_{k}\right)}\left(\frac{x_{n}}{x_{k n}}\right)\right]^{-1}, \quad y_{k} \geq y\right\}$.

Finally, on page 181, the second part of expression (10) must read: $A E_{i}^{C}(x, y, p) \underset{<}{<} A E_{i}^{N C}(x, y, p)$.

Addresses of authors: - Walter Briec, GEREM, Université de Perpignan, 54 Avenue Villeneuve, 66000, Perpignan, France, (e-mail: briec@univ-perp.fr) Kristiaan Kerstens CNRS-LEM, IESEG, 3 rue de la Digue, 59800, Lille Cédex, France (e-mail: k.kerstens@ieseg.fr) - Philippe Vanden Eeckaut GREMARS, Université Lille 3, Domaine Universitaire du "Pont de Bois", BP 149, 59653, Villeneuve d'Ascq Cédex, France (e-mail: philippe.vandeneeckaut@univlille3.fr) 